\title{
MAIO DE 1968 E JUNHO DE 2013: UMA LEITURA À LUZ DA OBRA DE HENRI LEFEBVRE ${ }^{1}$
}

\section{MAY 1968 AND JUNE 2013: A READING IN THE LIGHT OF HENRI LEFEBVRE'S WORK}

\author{
João Luiz Stefaniak"
}

RESUMO: O presente artigo busca contextualizar, tendo como escopo a obra de Henri Lefebvre, os acontecimentos ocorridos em Junho de 2013, que, a partir da manifestação contra o aumento da tarifa do transporte coletivo em São Paulo, repercutiram em todo território nacional, levando uma inusitada multidão de pessoas a protestarem em diversas cidades brasileiras. Para tanto, se faz necessário estabelecer um quadro comparativo de Junho de 2013 com Maio de 1968, uma vez que a reflexão lefebvriana acerca daquele movimento ocorrido na França é fundamental para estabelecer os elementos balizadores do entendimento do autor acerca das manifestações de massa. Contestação, espontaneidade e protagonismo juvenil são elementos coincidentes entre ambas as manifestações, conforme pode-se depreender da análise apresentada por Lefebvre. Além destas características comuns, está presente também a perspectiva utópica destes movimentos.

PALAVRas chaves: Junho de 2013; Maio de 2018; utopia.

AвSTRACT: This article seeks to contextualize, under the scope of Henri Lefebvre's work, the events that occurred in June 2013, which, as a result of the demonstration against the increase in the collective transportation fare in São Paulo, had repercussions throughout the national territory, leading an unusually large number of people to protest in several Brazilian cities. To do so, it is necessary to establish a comparison between June 2013 and May 1968, since the lefebvrian reflection on the movement in France is fundamental to establish the elements that guide the author's understanding of mass manifestations. Contestation, spontaneity and juvenile protagonism are matching elements between both manifestations, as can be deduced from the analysis presented by Lefebvre. In addition to these common features, is also present the utopian perspective of these movements.

KEY words: June 2013; May 2018; utopia.

\footnotetext{
${ }^{1}$ Este artigo foi elaborado a partir da pesquisa realizada no Curso de Doutorado em Geografia tendo como orientador o Prof. Dr. Luiz Alexandre Gonçalves Cunha. A pesquisa desenvolvida foi patrocinada pela CAPES.

* Doutor em Geografia pela Universidade Estadual de Ponta Grossa. Email: joaoluiz@stefaniak.com.br.
} 
Naquele final de outono do ano treze do Século XXI, tendo como palco as ruas e praças brasileiras, explode um amplo movimento de massas até então inusitado. Tendo como ponto de partida os protestos convocados pela juventude paulistana contra o aumento da tarifa dos ônibus de transporte coletivo, gigantescas manifestações vão tomar conta do país.

O jornalista Alan Gripp, em um artigo publicado em dezembro de 2013 na Folha de São Paulo, intitulado "Não era pelos vinte centavos", registrou que "quando um grupo de jovens se reuniu no dia 6 de junho na Avenida Paulista para contestar o aumento da tarifa de ônibus de São Paulo" (GRIPP, 2013, p. 2) ninguém imaginava que seria o estopim de um movimento de protesto de magnitude equivalente à da campanha das "Diretas Já" e do "Fora Collor". Esta frase sintetiza o sentimento de surpresa, e que em alguns casos beirou a total perplexidade, que tomou conta da opinião pública e dos analistas políticos quanto à dimensão que os protestos viriam a adquirir no decorrer daquele mês de junho.

A rapidez e a potência dessas manifestações que irromperam nas ruas brasileiras naquele fim de um abafado outono trouxe ao imaginário de vários autores e articulistas a ideia do raio. A expressão "raio em céu azul” é citada por Marcelo Pomar e Rudá Ricci (JUDENSNAIDER et al., 2013, p. 8) (RICCI \& ARLEI, 2014, p. 17). Léo Lince escreve "com a repentina rapidez dos relâmpagos", em artigo publicado em livro de autoria de Chico Alencar (ALENCAR, 2013, p. 39). Ainda nesta linha, Marco Aurélio Nogueira inicia sua obra sobre o tema com a frase "em junho de 2013, quando tudo parecia caminhar suavemente no Brasil" (NOGUEIRA, 2013, p. 31) e Manuel Castells, em obra acerca dos protestos ocorridos em 2011 em diversos países do mundo, introduz, no posfácio da edição brasileira, que o mesmo tipo de manifestação aconteceu também no Brasil “sem que ninguém esperasse” (CASTELLS, 2014, p. 178). Raquel Rolnik, na introdução de "Cidades Rebeldes", faz referência a "um trovão em um céu aparentemente sereno" (MARICATO et al., 2013, p. 8), e complementa:

pensar essas manifestações como um terremoto (...) que perturbou a ordem de um país que parecia viver uma espécie de vertigem benfazeja de prosperidade e paz, e fez emergir não uma, mas uma infinidade de agendas mal resolvidas, contradições e paradoxos. (MARICATO et al., 2013, p. 8)

Esta surpresa ou perplexidade em relação a Junho de 2013 é com certeza instigadora, e desafia a se inserir no debate acerca deste fenômeno social tão complexo. Parâmetros comparativos necessariamente surgem desta reflexão, pois a tendência é buscar entender Junho de 2013 a partir das manifestações massivas vivenciadas pela sociedade brasileira nas décadas finais do século passado - as Diretas Já (1984) e o Fora Collor (1992) -, ou pela equiparação aos protestos que afloraram em 2011 nos Estados Unidos, no mundo árabe e na Espanha: Occupy Wall Street, Primavera Árabe e Los Indignados, respectivamente. 
A intenção de mergulhar neste oceano de perplexidade e buscar contribuir para desatar o nó górdio de Junho de 2013 é o fio condutor deste artigo. Não há necessidade de sustentar o nível de complexidade do fenômeno, que é evidente. Muitas questões surgem desta reflexão, sendo que será desenvolvida neste artigo a análise dos fenômenos sociais a partir da contribuição de Henri Lefebvre, em especial da sua obra Revolução Urbana, pública à luz dos acontecimentos de Maio de 1968, em França.

Quando falamos de revolução, via de regra, estamos associando a uma transformação radical e abrupta e geralmente violenta da realidade política, social, econômica ou cultural, ou, simultaneamente, de toda a sociedade. Como consequência, as revoluções quase sempre se traduzem na ruptura com a ordem estabelecida e resultam de processos acumulativos de transformações históricas pontuais. Florestan Fernandes, no artigo “O que é revolução?", publicado no início dos anos 80 do século passado, mas ainda referenciado, afirma que "mesmo na linguagem de senso comum, sabe-se que a palavra [revolução] se aplica para designar mudanças drásticas e violentas da estrutura da sociedade. (...) uma mudança que "mexe nas estruturas", que subverte a ordem social imperante na sociedade” (FERNANDES, 2000, fl. 56).

Mas outro aspecto do conceito de revolução será relevado neste artigo. Revolução, historicamente, traz em seu bojo a ideia da mudança. Neste contexto, revolução significa a concretização do devir que se consubstancia na materialização de um projeto de transformação virtualmente concebido. Aqui, revolução se aproxima da Utopia. Outro aspecto é que, também do ponto de vista histórico, a revolução não se caracteriza por um determinado momento de ruptura apenas, mas por todo um "processo revolucionário" com desencadeamento de vários acontecimentos. Então, a questão a ser enfrentada no artigo é sobre o caráter revolucionário de Junho de 2013. Seriam os acontecimentos de Junho de 2013 prenúncio de um processo de transformação radical das estruturas do sistema capitalista? Tentar-se-á responder está questão a partir da contribuição encontrada na obra de Henri Lefebvre.

O filósofo e sociólogo francês Henri Lefebvre (16 de junho de 1901 - 29 de junho de 1991) nasceu na pequena comuna de Hagetmau, no departamento de Landes, região da Aquitânia, no extremo sudoeste da França. Graduou-se em 1920 em filosofia na Universidade de Paris. Em 1961, Lefebvre tornou-se professor de sociologia na Universidade de Estrasburgo, antes de se juntar à nova Universidade de Paris Nanterre em 1965.

Autor prolífico, a obra de Henri Lefebvre é bastante extensa, sendo que escreveu mais de setenta livros, abrangendo análises do marxismo do século XX. Entre as décadas de 50 e 60 do século passado, dedicou-se aos estudos sobre a questão agrária e, em 1963, publica "La vallée de Campan - Etude de sociologie rurale", sua tese de doutoramento em sociologia. Ingressou no Partido Comunista Francês (PCF) em 1928 e se tornou um dos mais proeminentes intelectuais marxistas franceses durante o segundo quarto do século passado, antes de se juntar à Resistência Francesa. De 1944 a 1949, foi diretor da "Radiodiffusion Française”, uma emissora de rádio francesa em Toulouse. Publica, em 1947, “Critique de la vie quotidienne”, considerado seu primeiro 
trabalho sobre o método regressivo-progressivo, empregado centralmente por Jean Paul Sartre em "A crítica da razão dialética" (1960). Durante toda sua militância, mantém no PCF intenso debate com grandes filósofos da época, incluindo o próprio Sartre, opondo-se aos marxistas ortodoxos e criticando os estruturalistas althursserianos. Segundo Sérgio Martins, estes embates 'Ihe custaram a periferia dos panteões institucionais lastreados por um 'pensamento' cada vez mais circunscrito ao economicismo e aos dogmatismos" (LEFEBVRE, 2008, p. 8).

No Brasil, Henri Lefebvre é principalmente conhecido pela criação do termo "direito à cidade", com o qual defendeu o direito ao acesso à vida urbana, e que foi desenvolvido no livro de mesmo nome publicado em 1968 em francês: "Le droit à la ville". Em seus estudos, marcadamente otimistas, recusava-se a criar modelos teóricos e a estabelecer programas de desenvolvimento acabados. Sua teoria não possui contornos fixos, pois, sob a influência do filósofo alemão Friedrich Nietzsche, a linguagem de Lefebvre possui algo de poético, numa clara tentativa de reencontrar a totalidade do social, possível pela "obra", em oposição ao "produto" resultado do trabalho alienado. Sua contribuição para a geografia foi mais profunda, pois toda a teoria atual desta disciplina se deve à tese de que o espaço é social, ou seja, socialmente produzido, influenciando grandes nomes da geografia do final do último século, tais como David Harvey e Milton Santos.

Durante as décadas de sessenta e setenta do século passado, Henri Lefebvre ocupou-se em refletir sobre a temática do urbano e da cidade. Deste período, destacam-se as obras " $L a$ droit à la ville" (1968), "Du rural à l'urbain" (1970), "La révolution urbaine” (1970), "La pensée marxiste et la ville" (1972), "Espace et politique" (1973) e "La production de l'espace" (1974). Além destes livros referentes a esta temática, o presente artigo vai explorar a obra "La Irrupcion: de Nanterre au somment" (1968), que, no Brasil, pode ser encontrada no livro cujo título é "A irrupção - a revolta dos jovens na sociedade industrial: causas e efeitos".

A hipótese teórica da sociedade urbana como sucedânea da sociedade industrial, que corresponde à atual fase do desenvolvimento do capitalismo, é exposta na obra de Henry Lefebvre intitulada "A Revolução Urbana". Vale frisar que, ao empregar termo "revolução urbana", Henri Lefebvre situa uma transformação em andamento e, fiel ao método regressivo-progressivo, parte de uma reflexão de uma realidade futura e virtual para tentar compreender o presente e justificar o passado. É neste sentido que a utopia está presente como forma de projetar uma estratégia que perpassa não apenas pela análise do real, mas pela identificação de problemas potenciais e de concepções imaginativas, ligadas à reflexão de um futuro possível. Aliás, para Henri Lefebvre, a utopia é imprescindível para a construção do pensamento, como afirma:

Lembro uma tese que tive a oportunidade de sustentar aqui e alhures. Hoje, mais que nunca, não existe pensamento sem utopia. Ou então, se nos contentarmos em constatar, ratificar o que temos sob os olhos, não iremos longe, permaneceremos com os olhos fixados no real. Como se diz: seremos realistas... mas não pensaremos! Não existe pensamento 
que não explore uma possibilidade, que não tente encontrar uma orientação." (LEFEBVRE [1973], 2008, 73)

Nesta mesma linha, segue David Harvey ao contextualizar a luta pelo direito à cidade. No atual período, afirma que este "não é simplesmente o direito ao que já existe na cidade, mas o direito de transformar a cidade em algo radicalmente diferente" (HARVEY, 2009), sendo que esta transformação deve estar assentada em uma prática que vai além da constatação do real, transpondo a realidade através de um projeto que vá de encontro de forma clara aos interesses do capital.

Neste mesmo sentido, Henri Lefebvre propõe uma utopia baseada nas experiências vividas no cotidiano das pessoas, pois qualquer pensamento crítico deveria gerar uma reflexão sobre o futuro, sendo que a utopia deve assumir este caráter experimental.

A utopia deve ser considerada experimentalmente, estudando-se na prática suas implicações e consequências. Estas podem surpreender. Quais são, quais serão os locais que socialmente terão sucesso? Como detectá-los? Segundo que critérios? Quais tempos, quais ritmos de vida cotidiana se inscrevem, se escrevem, se prescrevem nesses espaços "bem-sucedidos", isto é, nesses espaços favoráveis à felicidade?" (LEFEBVRE, 2004, p. 108)

Vale frisar que o pensamento lefebvriano antagoniza de forma bastante contundente as experiências vividas no cotidiano das pessoas que buscam a efetivação do direito à cidade, com a cidade concebida nos "planos" dos urbanistas que, via de regra, reproduzem a ideologia capitalista, caracterizada pelo pensamento fragmentado do urbano. Para Lefebvre, o urbanismo trata-se de um pseudoconceito do urbano, "isto é, aplicação da racionalidade industrial e evacuação da racionalidade urbana.” (LEFEBVRE, 2006, p. 48)

Henri Lefebvre propõe uma maneira de se pensar o fenômeno urbano e de relacionar o real com o virtual que denomina de "transdução". Neste contexto, os intelectuais que estudam o espaço, como geógrafos, arquitetos, urbanistas, sociólogos, economistas, políticos e filósofos, têm o papel de realizar este exercício mental com o objetivo de gerar uma utopia possível que anteveja as novas formas e relações presentes na sociedade urbana.

As pessoas acima relacionadas, tomadas separadamente ou em equipe, podem limpar o caminho; também podem propor, tentar, preparar formas. E também (e sobretudo) podem inventariar a experiência obtida, tirar lições dos fracassos, ajudar o parto do possível através de uma maiêutica nutrida de ciência." (LEFEBVRE [1968], 2004, p. 107)

Contra a fragmentação do racionalismo pseudocientífico, Henri Lefebvre pensa o urbano como totalidade, considerando sua permanente capacidade de mutação, a partir de 
uma dialética onde a práxis política, a utopia e a imaginação, são criadoras de uma estratégia única: a estratégia urbana. $E$ acrescenta que esta estratégia do conhecimento não pode ficar isolada, pois: "Ela visa a prática, ou seja, em primeiro lugar, uma confrontação incessante com a experiência e, em segundo lugar, visa a constituição de uma prática global, coerente, a prática da sociedade urbana." (LEFEBVRE, 2006, p. 131)

A partir destas reflexões, pode-se introduzir os acontecimentos de Junho de $2013 \mathrm{em}$ uma perspectiva de luta pelo direito à cidade, onde claramente se pauta a confrontação da realidade urbanística imposta pelo capital e a busca pela transformação desta realidade a partir da experiência vivida e a construção de um projeto urbano emancipador. O artigo esmiúça alguns dos elementos que apontam que Junho de 2013 não pode ser interpretado meramente como um fenômeno espontâneo, fruto de uma indignação alienada e pontual. Junho de 2013 expressa algo muito mais profundo: ele pode ser entendido como um processo de construção de uma nova utopia. Uma utopia que pode ser a antevisão da revolução urbana.

A comparação com os acontecimentos de Maio de 1968 na França é imprescindível para buscar a compreensão de Junho de 2013 sob a luz da obra de Lefebvre. O Movimento de 22 de Março de 1968, que foi estopim para os fatos que se seguiram, foi um protesto onde cerca de cento e cinquenta jovens estudantes da Faculdade de Letras da Universidade de Paris Nanterre ocuparam os serviços administrativos da Faculdade de Letras, em protesto contra a prisão de seis estudantes que, dias antes, tinham se manifestado contra a guerra do Vietnam. Ninguém imaginaria que aquele pequeno, mas audacioso ato viesse a desencadear uma avalanche de manifestações, que culminou com uma greve geral que se estabeleceu em todo território francês, mobilizando dez milhões de trabalhadores - cerca de dois terços da força de trabalho - da França. Igualmente, ninguém imaginava que os protestos de 6 de junho de 2013 contra o aumento da tarifa do transporte coletivo em São Paulo gerasse uma onda de protestos de tamanha magnitude como visto nos capítulos anteriores da tese.

A repressão policial que seguiu ao ser decretado o fechamento dos cursos pelo reitor da Universidade de Nanterre impulsionou a adesão dos estudantes a partir de 3 de maio de 1968, da mesma forma que a revolta popular contra a violência imposta aos os manifestantes paulistanos e cariocas aumentou a adesão a Junho de 2013.

No entanto, diferentemente de Junho de 2013, a adesão da Confédération Générale du Travail, a federação sindical de esquerda ligada ao Partido Comunista Francês (PCF), teve um forte impacto no movimento inicial, sendo que, além dos protestos estudantis, as greves e ocupações de fábricas marcaram os acontecimentos de Maio de 1968.

Após os acontecimentos de Maio de 1968, o governo presidido por Charles de Gaulle chegou à beira do colapso, tendo que antecipar as eleições parlamentares para 23 de junho. A partir de junho de 1968, os protestos arrefecem e as últimas manifestações estudantis são duramente reprimidas. Nas eleições que se seguiram, o partido ghoullista saiu fortalecido e os protestos cessam em todo território francês. 
Henri Lefebvre viveu no olho do furacão do Maio de 1968, e seu cotidiano, que provavelmente incluía caminhadas pela Place de La Defense, perto de onde lecionava, na Faculdade de Letras da Universidade de Paris Nanterre, foi abalado pela insurreição estudantil. Tinha acabado de publicar "Droit à la Ville", e com certeza os fatos que presenciava naquela tumultuosa primavera parisiense lhe pareciam um grande laboratório social onde as suas teses e proposições poderiam ser testadas. Ainda no calor da rebelião juvenil de Maio de 68, elaborou um ensaio intitulado "La Irrupcion: de Nanterre au somment" que talvez permita, em um sucinto quadro comparativo, ajudar na decifração do enigma surgido a partir de Junho de 2013.

O sociólogo Leo Lince, no seu artigo "Irrupção, fim de ciclo e interregno", analisa Junho de 2013 sob a ótica dos acontecimentos de Maio de 1968 e da obra lefebvriana:

Henri Lefebvre, um marxista atento às réplicas da história, ao analisar ainda no calor das refregas a rebelião juvenil de maio de 68 na França, sacou conclusões que, talvez, possam nos ajudar na decifração do enigma atual. Estavam presentes na crise de então - as "barricadas do desejo" em Paris e a greve geral que paralisou a sociedade francesa por semanas - todos os ingredientes que no protocolo da esquerda definem uma típica "situação revolucionária". Mas, segundo Lefebvre, não haveria revolução. Sequer se produziria, como de fato não se produziu, uma momentânea "dualidade de poder". Por conta de características elencadas em tempo real, a gigantesca onda contestatória que não desemboca em revolução ou contrarrevolução foi chamada por Lefebvre de irrupção. (LINCE, 2013, p. 1)

Para Leo Lince, a irrupção contestatória seria um tipo de movimento que revelava a emergência de novas contradições no solo cristalizado da política. "Contradições nascidas por acréscimo, superpostas às antigas que foram atenuadas, dissimuladas, "reduzidas", sem que nunca tenham sido resolvidas, no interior dos jogos do poder." (LINCE, 2013). E continua a análise destas contradições que vão desencadear a irrupção contestatória, reforçando a oposição política, que se amolda ao "aparato total", deixando de expressar a dinâmica dos conflitos que ficam contidos na base da sociedade e "quando os chamados 'corpos intermediários' se mostram momentaneamente absorvidos pela rotina da repetição do 'mesmo', entre a política institucional e a chamada sociedade civil abre-se um imenso vazio." (LINCE, 2013, p. 1).

E é justamente para preencher tal vazio que brota a onda contestatória. E acrescenta Leo Lince:

Ela [a onda contestatória] carrega a suprema pretensão de substituir, recompor, refazer a partir do zero as mediações sociais e políticas por intermédio das quais as demandas deveriam se elevar ao nível global. Ao constatar a ineficácia dos partidos e dos "corpos intermediários" cooptados pela lógica do poder dominante, a contestação se volta contra 
o institucional em geral. Questiona a política, mas não é despolitizada. Expressa e aspira outro tipo de política. Ao contrário da política regular-profissional, não trabalha na perspectiva de "acumulação de forças" no interior de uma determinada racionalidade política. O sentido imediato da onda contestatória é o da recusa à integração. Nasce das profundezas, abaixo das raízes da vida social organizada, de costas para o Estado e longe de suas instituições. Para usar uma expressão feliz de Lefebvre, são movimentos localizados "abaixo da base". (LINCE, 2013, p. 1).

O artigo de Leo Lince enfatiza o papel da juventude nos acontecimentos de Maio de 1968, partindo da definição dada por Henri Lefebvre. A juventude, para o filósofo das cidades, não é entendida apenas como uma determinada faixa etária, e sim, parafraseando o sociólogo franco-argelino Jacques Berque, se define mais como uma "relação com o mundo" (LEFEBVRE, 1968, p. 111), e é, por excelência, o agente da irrupção contestatória, sendo que tanto em Maio de 1968 como em Junho de 2013 o jovem teve um papel social "antirredutor" no interior do sistema.

Outro aspecto destacado por Henri Lefebvre em sua análise dos acontecimentos de Maio de 1968 foi a espontaneidade. Para ele "a contestação nasce espontaneamente. Ela se define como espontaneidade, com o horizonte e os limites da espontaneidade" (LEFEBVRE, 1968, p. 112), e acrescenta:

Sem espontaneidade, não haveria nenhum acontecimento, nenhum movimento. Nada aconteceria. Por conseguinte, para todos os poderes a espontaneidade é o inimigo. Sem que, por isso, ela se constitua num poder. Têm condições, portanto um sentido. (LEFEBVRE, 1968, p. 113).

Lefebvre contrapõe a crítica à espontaneidade leninista, que, segundo ele, conduz a uma percepção dogmática que nega e condena o espontâneo a algo irracional, a ponto de considerá-lo algo nulo. Contrariamente, Lefebvre vê um sentido na espontaneidade dos acontecimentos, que somente pode ser definido para além do institucional. O locus da espontaneidade é a rua, pois "na rua [em Maio de 1968] se manifestou a espontaneidade: no lugar social não ocupado pelas instituições" (LEFEBVRE, 1968, p. 114). Leo Lince explana desta forma este aspecto da irrupção lefebvriana:

Mas, como no caso analisado por Lefebvre, a irrupção não se configura como um polo ordenado de lutas, no qual se condensam vetores orientados por alternativas programáticas bem delineadas. Pelo contrário. Há de tudo na babel de vozes que toma de assalto o espaço livre das ruas. Pululam postulações desencontradas. A falência do modelo dominante e o ocaso de um ciclo político não aparecem como resultante do acúmulo ordenado de pequenas mudanças. A crise se mostra na forma da fratura exposta. A explosão contestatória abala o mundo da política, desloca o eixo em torno do qual tal mundo gira, mas o seu clarão, por si só, não 
ilumina caminhos de mudança. É um fenômeno que, por sua própria natureza, dispara variáveis fora de qualquer controle. Diante do agito colossal, todos se assustam: ninguém hegemoniza e, ao mesmo tempo e pela mesma razão, de imediato ninguém se sente interditado por ele. Daí o espetáculo das múltiplas leituras interessadas, dos recuos táticos, da busca rápida de "agendas positivas" que possibilitem acertar o passo com o ritmo da novidade que chegou para ficar sem ter dito, ainda, a que veio. (LINCE, 2013, p. 1)

Contestação, espontaneidade e protagonismo juvenil são elementos evidentes que confluem e se relacionam nos acontecimentos de Maio de 2018 e Junho de 2013. São os aspectos exteriorizados da irrupção lefebvriana que somente podem ser compreendidos em sua profundidade a partir do conceito de "mutação" que prenuncia, no artigo agora analisado, a tese da "sociedade urbana", e que somente vai ser consolidada em "La Revolution Urbaine". Henri Lefebvre parte do conceito de "Movimento" sem se preocupar em defini-lo, mas sim em situá-lo espacialmente, pois "a teoria do movimento só pode provir do próprio movimento" (LEFEBVRE, 1968, p. 133). Em seguida, o "filósofo da cidade" engendra uma reflexão a partir dos fenômenos urbanos: inicialmente, situa Nanterre, a "faculdade parisiense fora de Paris". Localizada no subúrbio, a Faculdade convive com as favelas e as moradias proletárias. A segregação espacial e sexual (com a separação entre moças e rapazes) se apresenta como um vazio e a "ausência é o lugar onde a infelicidade assume uma forma". Distante, a Cidade passa a ter um valor utópico para "as moças e rapazes instalados na 'heteropia' geradora de tensões" e "torna-se o lugar das aspirações e das rebeliões sexuais" (LEFEBVRE, 1968, p. 135). E a faísca acesa em Nanterre chega ao Quartier Latin: o rastilho segue o caminho do subúrbio para o centro de Paris, e o movimento "vai se deslocar sobre um novo terreno", e as "pessoas vindas da periferia, do exterior em que foram projetadas, onde só encontraram um vazio social, se reúnem e vão em direção aos centros urbanos para reconquistá-los.” (LEFEBVRE, 1968, p. 143). Por fim, em um terceiro momento, o Movimento se amplia de forma impressionante, e ganha novamente a periferia, com a adesão massiva do operariado francês. É o auge do Movimento que depois reflui. "A ocupação maciça dos locais de produção, as reivindicações potentemente sustentadas, mas parciais fazem esquecer que os locais do poder e os centro de decisão retomaram suas funções." (LEFEBVRE, 1968, p. 146). A Cidade não é mero palco dos acontecimentos. A irrupção descrita por Henri Lefebvre é um "fenômeno urbano" por excelência, sustenta Leo Lince, e novamente Junho de 2013 e Maio de 1968 confluem:

Seu impulso [da irrupção] é habitado por aspirações grandiosas de reconstruir a sociedade através de um tipo de exercício democrático radical, constituinte e instituinte, onde todos os conflitos e interesses estariam, mais do que representados, presentes em ato, nas ruas e praças, ou seja, nos lugares ainda não totalmente controlados pelas amarras do sistema dominante. São momentos fugazes, onde se vive 
a ilusão do exercício pleno da recomposição do corpo da política. São movimentos de larga envergadura e que, quase sempre, remetem para o ciclo longo e para o prazo largo. No conjuntural imediato, tais movimentos se destinam a produzir um tipo original de interferência no processo concreto da luta política. (LINCE, 2013, p. 1)

O Movimento não pode prescindir do seu sentido de mudança, de "mutação". Apesar de recusar defini-lo, Lefebvre busca caracterizá-lo pela sua práxis.

Não foi este ou aquele pensamento político [se refere aos pequenos círculos revolucionários, trotskistas, maoistas, etc.] que mostrou sua eficácia, foi antes o ato inicial de um pensamente que se recusa a condição anterior, um ato coletivo, apesar das divergências, que permitiu a formação do movimento. (LEFEBVRE, 1968, p. 139)

Tal como aconteceu em Junho de 2013, em Maio de 1968 emerge uma nova prática, calcada na negação aos agentes políticos tradicionais. A irrupção é um grande laboratório, onde são gestadas novas formas de se pensar e fazer a ação política:

A irrupção contestatória costuma semear novidades (novas lideranças, nova pauta de debates, novos sujeitos, nova morfologia na estrutura dos movimentos) que se destinam a produzir, como bombas de efeito retardado, alterações profundas na cultura política. Nem sempre na conjuntura imediata, mas no entranhado das estruturas. (LINCE, 2013)

Finalmente, a "mutação" delineada por Henri Lefebvre vai repercutir nas análises e formulações anunciadas na sua obra "La Droit à la Ville", destacando a "integração dos centros e das periferias" anunciando uma "nova esfera social, política, cultural: a sociedade urbana". Lefebvre observa que "A centralidade obtida e conservada pelo movimento o envia para as margens da realidade urbana" e "dessas margens, o movimento repercute e volta aos centros de decisão”. (LEFEBVRE, 1968, p. 147).

Os acontecimentos de Maio de 1968 permitem a Lefebvre a percepção da sociedade urbana que se anuncia enquanto projeto e que se estabelece na explosão, então em curso na cidade. A "base" material e social desta sociedade urbana se manifesta na superação das segregações e das dissociações múltiplas inerentes à cidade capitalista.

No desenvolvimento desigual da sociedade, em cima das contradições antigas e novas, três camadas de superestruturas (instituições, ideologias) se sobrepõem, não sem interações:

a) Superestruturas datando da época pré-capitalista, quando predominavam ainda a produção agrícola e a vida rural, com suas imagens e suas representações de mundo; 
b) Superestruturas datando da industrialização, nos quadros sociais determinados pela burguesia, o capitalismo, a propriedade privada dos meios de produção (lembrando que a base técnica de industrialização não para de se transformar: automação, informática).

c) Superestruturas incertas, ainda mal definidas, incitadas pela transformação da sociedade que se opera nos quadros já definhantes (em outras palavras: os quadros da sociedade de consumo, do capitalismo de organização ou capitalismo monopolístico ligado ao Estado). Essa transformação em profundidade se define como sociedade urbana em gestação que emerge com sua problemática e suas exigências. (LEFEBVRE, 1968, p. 143)

Dos elementos apontados acima, a partir dos textos de Henri Lefebvre, pode-se afirmar que a irrupção contestatória, o protagonismo juvenil e sua espontaneidade, além da novidadeira práxis política do movimento, são encontradas e fundamentadas pela análise de Leo Lince ao comparar os acontecimentos de Maio de 1968 e Junho de 2013. Já quanto à "mutação" que induz a sociedade urbana, apesar de reconhecer o caráter urbano dos fenômenos, ela não é salientada por este articulista.

A comparação dos acontecimentos ocorridos em França em 1968 e no Brasil em 2013 é fundamental em qualquer análise cujo referencial teórico parte da contribuição de Henri Lefebvre. É importante salientar que tal quadro comparativo tem como pressuposto tanto a compreensão do desenvolvimento urbano desigual e combinado quanto a tese da "urbanização pretérita" brasileira, sustentada por Milton Santos, que justifica a atualidade do Maio de 1968 para se compreender Junho de 2013, mesmo considerando a distância temporal de quarenta e cinco anos que separa os eventos.

\section{REFERÊNCIAS}

ALENCAR, C. A rua, a nação e o sonho: uma reflexão para as novas gerações. Rio de Janeiro: Mar de Ideias, 2013.

CASTELLS, M. Redes de indignação e esperança: movimentos sociais na era da internet. Rio de Janeiro: Zahar, 2013.

\section{FERNANDES, F. O que é revolução? São Paulo: Expressão Popular, 2000.}

GRIPP. A. Não era pelos vinte centavos. Jornal Folha de São Paulo. Caderno Retrospectiva. 27 de dezembro de 2013.

HARVEY, D. Wall Street e o direito à cidade. Le Monde Diplomatique: Março de 2009. Disponível em: <http://www.polis.org.br> Acesso: 01 mar. 2011.

JUDENSNAIDER, E. et al. Vinte centavos: a luta contra o aumento. São Paulo: Veneta, 2013. 
LEFEBVRE, H. A revolução urbana. Belo Horizonte: Umanitas, 2008.

LEFEBVRE, H. O direito à cidade. São Paulo: Centauro, 2008.

LEFEBVRE, H. A produção do espaço. 2006. Disponível em: <http://www.mom.arq.ufmg.br/ mom/arq_interface/1a_aula/A_producao_do_espaco.pdf> Acesso 27 ago 2018.

LEFEBVRE, H. Espaço e política. Belo Horizonte: Editora UFMG, 2008.

LEFEBVRE, H. La presencia e la ausencia: contribuicion a la teoria de las representaciones. México: FCE, 2006.

LEFEBVRE, H. et al. A irrupção - a revolta dos jovens na sociedade industrial: causa e efeitos. São Paulo: Editora Documentos, 1968.

LINCE, L. Irupção, fim de ciclo e interregno. Disponível em: http://www.correiocidadania. com.br/colunistas/leo-lince/8794-30-08-2013-irrupcao-fim-de-ciclo-e-interregno. Acesso 28 jul. 2018.

MARICATO, E. et al. Cidades rebeldes: Passe Livre e as manifestações que tomaram as ruas do Brasil. São Paulo: Boitempo: Carta Maior, 2013.

RICCI, R.; ARLEY P. Nas ruas: a outra política que emergiu em junho de 2013. Belo Horizonte: Editora Letramento, 2014.

Recebido para publicação em 10 out. 2018. Aceito para publicação em 20 maio 2019. 